\title{
Commentary
}

\section{Here Comes the Sun}

\author{
DAVID J. ROTHMAN \\ Columbia University College of Physicians E Surgeons
}

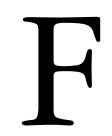

OR THE PAST 20 YEARS, FINANCIAL CONFLICTS OF INTEREST between physicians and drug and device companies have been a major concern for health care professionals and their organizations. In part, the attention reflects the impact of the extensive research demonstrating how conflicts of interest bias physician decision making. In part, too, it is a response to embarrassing media stories of doctors profiting from drug companies' largesse. Federal and state lawsuits also have highlighted how the industry's gifts and payments have been used to influence physician prescribing and institutional purchases. To cite one example: In 2012 and 2014, GlaxoSmithKline paid fines of more than $\$ 3$ billion to the US government to settle charges that it had lavishly entertained and compensated physicians to induce prescribing its drugs off-label. Although a handful of hard-core industry defenders try to minimize the impact of conflicts of interest, the task is pointless when between 2012 and 2013, Merck paid out \$950 million; J\&J, $\$ 2.2$ billion; Abbott, \$1.5 billion; and Amgen, \$762 million for fraudulent marketing practices (http://projects.propublica.org/ graphics/bigpharma).

Despite this record, policies governing conflicts of interest are not as rigorous as they might be or should be. The shortfall is not for lack of guidance on best practices. In 2006, the American Board of Internal Medicine, in collaboration with the Institute on Medicine as a Profession at Columbia University, issued a slate of recommendations for academic medical centers on managing conflicts of interest. ${ }^{1}$ More broadly, in 2009, the Institute of Medicine of the National Academies of Sciences issued a set of conflict-of-interest guidelines for physicians, biomedical scientists, and academic medical centers. ${ }^{2}$ Nevertheless, only about one-third of academic medical centers meet these standards. ${ }^{3}$ To be sure, their policies have strengthened over the past several years. Now most academic medical centers ban company meals and gifts, but they have a considerable distance to go, including more tightly regulating honoraria,

The Milbank Quarterly, Vol. 92, No. 3, 2014 (pp. 471-474)

(c) 2014 Milbank Memorial Fund. Published by Wiley Periodicals Inc. 
consulting, and speakers' bureaus. The performance of professional medical associations is even weaker. Although a few have rigorous policies, most have yet to reduce their reliance on industry funding or to make certain that activities such as formulating practice guidelines are completely independent of industry influence. By the same token, patient advocacy organizations still obfuscate their financial ties to industry, as do medical communication companies that organize continuing medical education (CME) courses. ${ }^{4}$

How has the US Food and Drug Administration (FDA) handled the issue? As Genevieve Pham-Kanter skillfully explains in this issue, the FDA has carried out several studies to calculate the extent of conflicts of interest among the members of its advisory group. But as she notes, FDA regulations have "waxed and waned." The FDA does ask would-be members for personal financial information and identifies those with financial conflicts on products under review. But the FDA also often issues "waivers" to allow participation despite the conflicts. Does it matter? After examining 15 years of meetings and almost 16,000 votes, Pham-Kanter reports that members having a financial relationship with only the sponsor are far more likely than other members to vote in favor of the sponsor's product. If the member is on the company's advisory board, it changes "the baseline probability of voting in favor of the sponsor from $52.1 \%$ to $84.4 \%$." She did find that members with multiple conflicts of interest are less biased. Nonetheless, medical professionalism, scientific integrity, and patient well-being will not be served by encouraging physicians to seek financial relationships with more companies.

Are we likely to see policy improvements in the near future? For the FDA, Pham-Kanter is somewhat optimistic, as its recent limit on the percentage of waivers issued is reducing the number of conflicted members (see her Figure 1 on page 464). But caution is still in order, since the FDA insists that its need for expertise may outweigh the risk of conflicts of interest, thereby ignoring the option of allowing experts to testify but not to vote.

That said, we do seem to be on the cusp of large-scale and dramatic changes, many of which may come in response to the implementation of the Sunshine Act. Beginning September 30, 2014, almost all industry payments to physicians will be posted under the recipient's name on a searchable government website. There will be a few exceptions; for example, industry payments to residents will not be reported. Payments to physicians made through third parties—essentially medical 
communication companies paying lecturers in continuing medical education courses-were initially exempt, but in July 2014 the Centers for Medicare and Medicaid Services proposed a rule altering this requirement which is now out for comment until September. This exemption was based on the highly dubious grounds that the Accreditation Council for Continuing Medical Education effectively polices biases. ${ }^{5}$

These limitations notwithstanding, we are entering an era of unparalleled transparency. Sunshine will bring simplicity and accuracy to obtaining and scrutinizing industry payment data. Rather than relying on individual physicians' disclosures, with all their imprecision and possible omissions, we will have company-compiled reports_-name, payment date, exact sum, and purpose-as compiled by their compliance departments and available for prior review by the named physicians. With a minimum of effort, medical school deans, hospital administrators, and leaders of professional medical societies will be able to consult the data when making teaching assignments, appointing formulary committees, establishing practice guideline committees or selecting speakers and commentators. Medical journal editors will be able to vet would-be authors and reviewers, and journalists will be able to vet possible interviewees. In addition, patients will be able to access the information, although based on their use of other data sets like surgical outcomes, their likelihood of doing so is low.

As Sunshine Act reports become embedded in institutional decision making, the FDA may also conform and appoint only nonconflicted physicians to advisory boards. The alternative may well bring a variety of penalties, like hostile questions from a Senator Charles Grassley at confirmation time or media exposés that go viral. The excuse that expertise always comes with conflicts is simply too flimsy.

Perhaps the most crucial change that the Sunshine Act may bring is a rise in the number of physicians unwilling to accept industry payments. Rather than accept a few hundred dollars for speaking or attending an advisory board meeting, physicians may decide that the money is not worth the bother of reviewing company figures; reporting their compensation to a dean, department chair, or professional medical society colleagues; and explaining it to inquisitive patients. (Anecdotally, this shift is already beginning.) Conversely, when thousands of dollars in royalty payments for a patented device are at stake, the time and effort may indeed seem worth it. 
To place these choices into a larger frame, Sunshine may help produce a 2-track profession: (1) a professional track for those who prefer to remain free of industry ties so as to simplify their clinical and organizational lives and allow their participation in various activities and (2) an entrepreneurial track for those who take pride in the size of their royalties. It is too soon to chart the outcomes, but it would be surprising if physicians did not behave differently when watched.

\section{References}

1. Brennan TA, Rothman DJ, Blank L, et al. Health industry practices that create conflicts of interest: a policy proposal for academic medical centers. JAMA. 2006;295(4):429-433.

2. Lo B, Field MJ, eds. Conflict of Interest in Medical Research, Education, and Practice. Institute of Medicine (US) Committee on Conflict of Interest in Medical Research, Education, and Practice. Washington, DC: National Academies Press; 2009. http://www.ncbi.nlm.nih.gov/books/NBK22942/.

3. Chimonas S, Evarts SD, Littlehale SK, Rothman DJ. Managing conflicts of interest in clinical care: the "race to the middle" at U.S. medical schools. Acad Med. 2013;88(10):1464-1470.

4. Rothman SM, Brudney KF, Adair W, Rothman DJ. Medical communication companies and industry grants. JAMA. 2013;310(23):2554-2558.

5. Agrawal S, Brennan N, Budetti P. The Sunshine Act-effects on physicians. N Engl J Med. 2013;368(22):2054-2057.

Funding/Support: Research for this article was conducted under a grant from the state Attorney General Consumer and Prescriber Education Grant Program.

Address correspondence to: David J. Rothman, Columbia University College of Physicians \& Surgeons, 630 West 168th St, P\&S Box 11, New York, NY 10032 (email:djr5@columbia.edu). 